\title{
International Research Interdisciplinary School : 23-28 September 2017, Semey, East Kazakhstan region,
} Kazakhstan

Raikhan Tuleutayeva ${ }^{1 a}$, Aygerim Mukhamedova $^{1 b}$, Aygerim Musina $^{1 \mathrm{a}}$, Zuhra Sultanova $^{1 \mathrm{c}}$, Assem Makhatova $^{1 \mathrm{a}}$, Michaela Vancova ${ }^{2}$, Alexandra Selivestrova ${ }^{1 \mathrm{~d}}$, Erkezhan Kalshabai ${ }^{1 \mathrm{e}}$, Roza Taimanova ${ }^{3}$, Samatbek Abdrahmanov ${ }^{1 \mathrm{f}}$, Natalia Kopuncova ${ }^{2}$, Gulnara Nurgalieva ${ }^{1 \mathrm{~g}}$, Ernar Mamyrov ${ }^{1 \mathrm{~h}}$, Dinara Alibekova ${ }^{4}$, Laura Pak ${ }^{1 \mathrm{~d}}$, Raisa Kuzdenbayeva ${ }^{5}$, Ljuba Bacharova ${ }^{6}$, Gulmira Kudaiberdieva7, Jonathan Lipton ${ }^{8}$

${ }^{1 \mathrm{a} D e p a r t m e n t}$ of Pharmacology and Evidence Based Medicine, ${ }^{1 \mathrm{~b}}$ Functional Diagnosis Department of University Hospital, ${ }^{1 \mathrm{C}}$ Department of Vascular Surgery, ${ }^{1 \mathrm{~d}}$ Oncology and Visual Diagnosis Department,

${ }^{1 \mathrm{e}}$ Department of Internal Medicine, ${ }^{1 \mathrm{f}}$ General Surgery Department, ${ }^{1 \mathrm{~g} O b s t e t r i c s \& G y n e c o l o g y}$ Department,

${ }^{1 h}$ Anesthesiology Department, Semey State Medical University, Semey, Kazakhstan

${ }^{2}$ Slovak Research Center, Slovakia

3 National Scientific Center of Surgery A.N.Sizganov, Almaty, Kazakhstan

${ }^{4}$ Oncology Center, Taraz, Kazakhstan

${ }^{5}$ Association of Clinical Pharmacologists and Pharmaceutics of Kazakhstan

${ }^{6}$ International Laser Center, Comenius University, Bratislava, Slovakia, Journal of Electrocardiology

${ }^{7}$ Heart Vessels and Transplantation Journal

${ }^{8}$ Department of Cardiology, Royal Hobart Hospital and Royal Melbourne Hospital, Hobart TAS, Australia

This year the International Research Interdisciplinary School (IRIS) were held in three locations in Slovakia and Kazahkstan. The purpose and methodology of the IRIS has been described in detail in previous reports (1-12). Participants in IRIS may increase the number of publications after compared to prior their participation (13). From September 23 to September 28 the IRIS was held at the sanatorium Stroitel, Semey, Kazakhstan. Far from the noisy city, resting from the city bustle and the intense rhythm of modern everyday life, enjoying the silence of the pine forest, young scientists had the opportunity to acquire the skills of scientific researches.

The school was organized by the Department of Pharmacology and Evidence- Based Medicine of the Semey State Medical University and Association of Clinical Pharmacologists and Pharmacists of the East Kazakhstan region under patronage of the Journal of Electrocardiology, Heart Vessels and Transplantation, journal of school initiative (13). The international faculty was represented by Ljuba Bacharova Executive Editor, Bratislava, Slovakia; Jonathan Lipton, Associate Editor of Heart Vessels and
Transplantation, Hobart, Australia; Gulmira Kudaiberdieva, Editor-in-Chief Heart Vessels and Transplantation.

The eleven participants were from Kazakhstan and Slovakia and of 9 different specialties, including anesthesiology, obstetrics and gynecology, oncology, clinical pharmacology, general surgery, clinical trial management, cardiothoracic surgery, physiology and general medicine. Participants were at different levels of experience including specialists, residents in training and PhD students:

Alibekova Dinara - oncology, Taraz, Kazakhstan; Taimanova Roza - cardiothoracic surgery, Almaty, Kazakhstan; Michaela Vancova - clinical trial management, Slovak Research Center, Slovakia; Natalia Kopuncova -clinical trial management, Slovak Research Center, Slovakia; Nurgalieva Gulnara obstetrics and gynecology; Mukhamedova Aigerim clinical physiology; Makhatova Assem - clinical pharmacology; Abdrahmanov Samatbek - general surgery; Mamyrov Ernar - anesthesiology (PhD student); Selivestrova Alexandra - oncology; Kalshabai Erkezhan - medicine, Semey, Kazakhstan.

Address for Correspondence: Jonathan Lipton, Department of Cardiology, Royal Hobart Hospital and Royal Melbourne Hospital, Hobart TAS 7000, Australia Email: jonathanlipton@gmail.com

Received: 13.11.2017 Accepted: 14.11.2017

Copyright@2017 Heart Vessels and Transplantation 

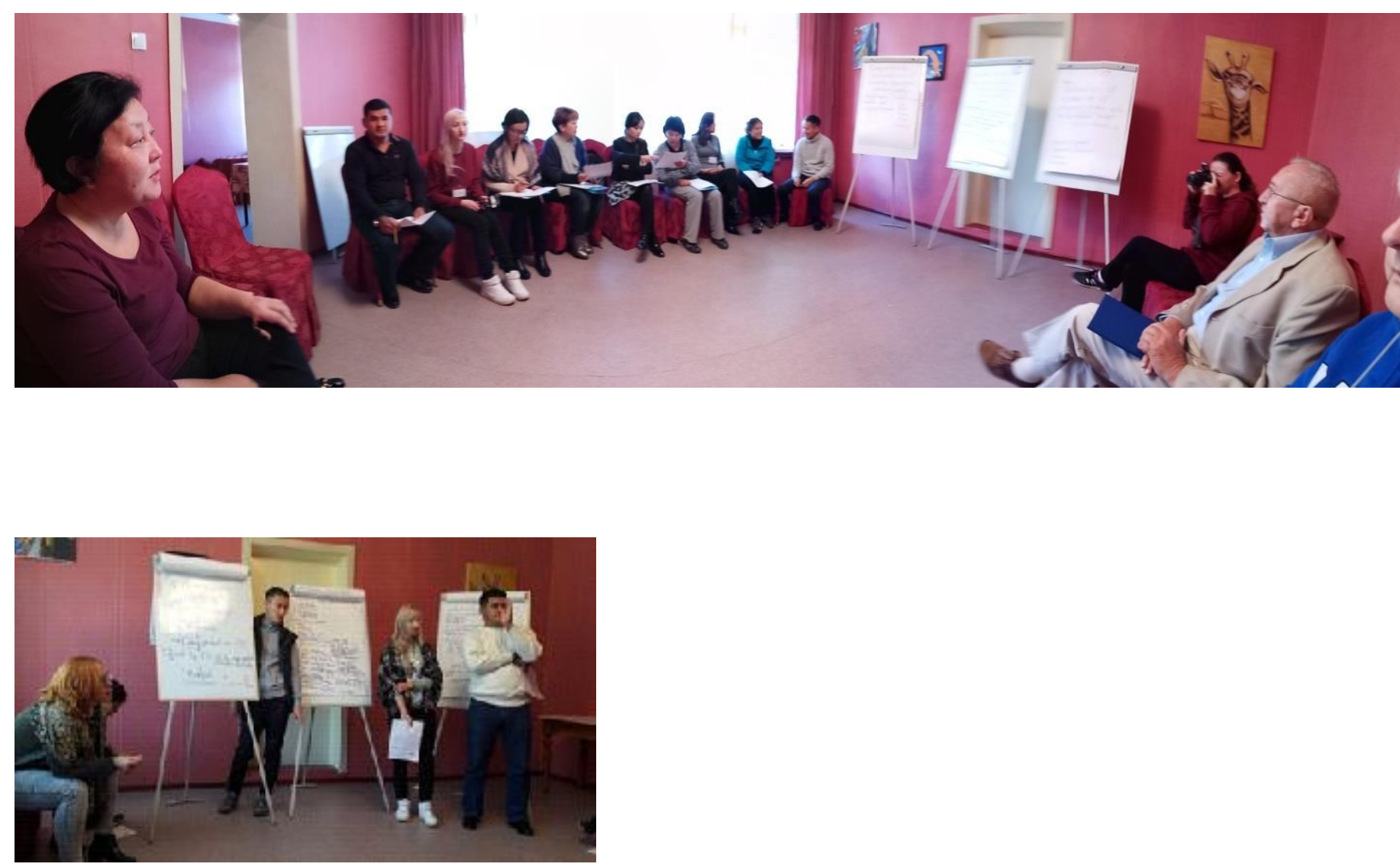

Figure 1. Panel discussion

Participants were divided into 3 research groups in order to obtain diversity in background, experience and nationality of the team members. During 4 days of workshops they prepared and presented the following projects:

Team "Sharks": Comparison of the gradient in Left Ventricular Outflow Tract (LVOT) in patients with obstructive hypertrophic cardiomyopathy after alcohol septal ablation and surgical myectomy".

Team "Hunters": The effect of cytokine therapy (CT) on the survival of patients with non-operable lung cancer (LC) receiving chemotherapy (CHT).
Team "The Girls": Prognostic significance of Lactate dehydrogenase (LDH) for maternal complications in the early onset severe pre-eclampsia.

Using a four workshop structure, each team developed a project, based on the theme chosen by the participants, and presented it to the entire audience. During the group discussions, the faculty guided interactive discussions providing feedback on the group projects. An additional session was held, at which faculty and participants exchanged their experiences on how to submit the manuscript and publish it in an international peer-reviewed journal. 


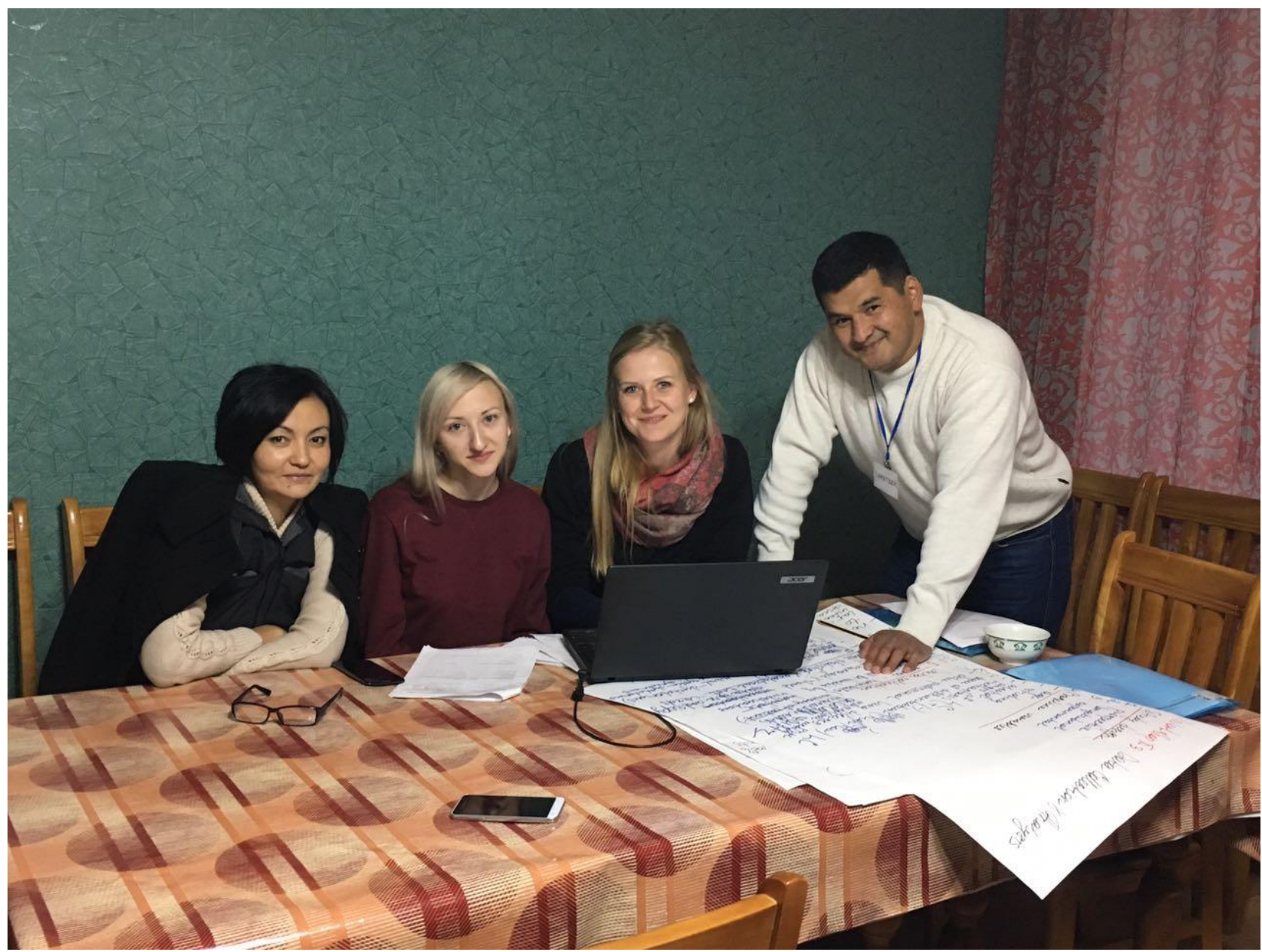

Figure 2. Team Hunters: Assem Makhatova, Alexandra Selivestrova, Natalia Kopuncova and Samatbek Abdrahmanov: storming in-doors warmly

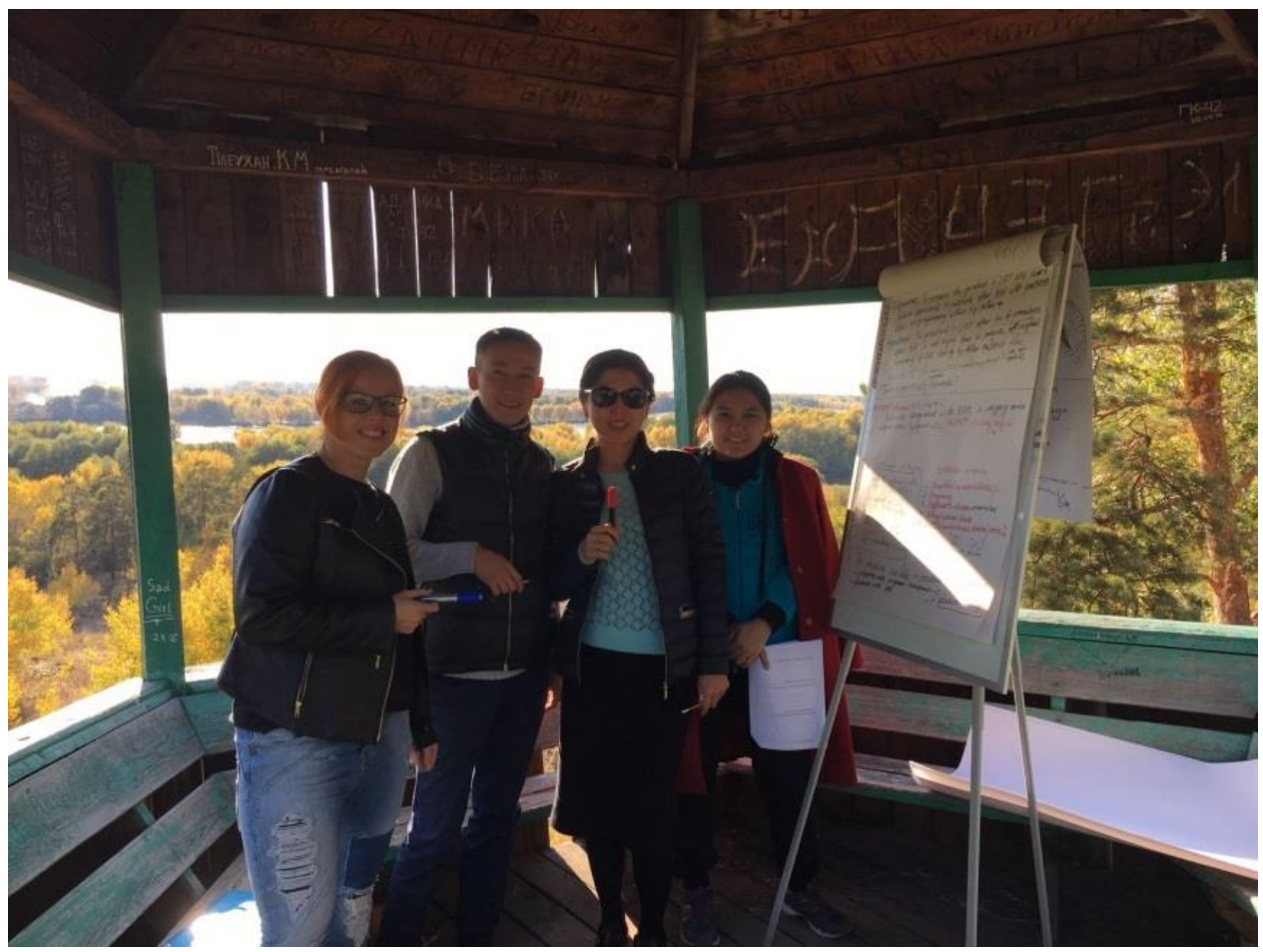

Figure 3. Team " Sharks": Michaela Vancova, Ernar Mamyrov, Aigerim Mukhamedova, Roza Taimanova - storming in splendid environement out-doors 


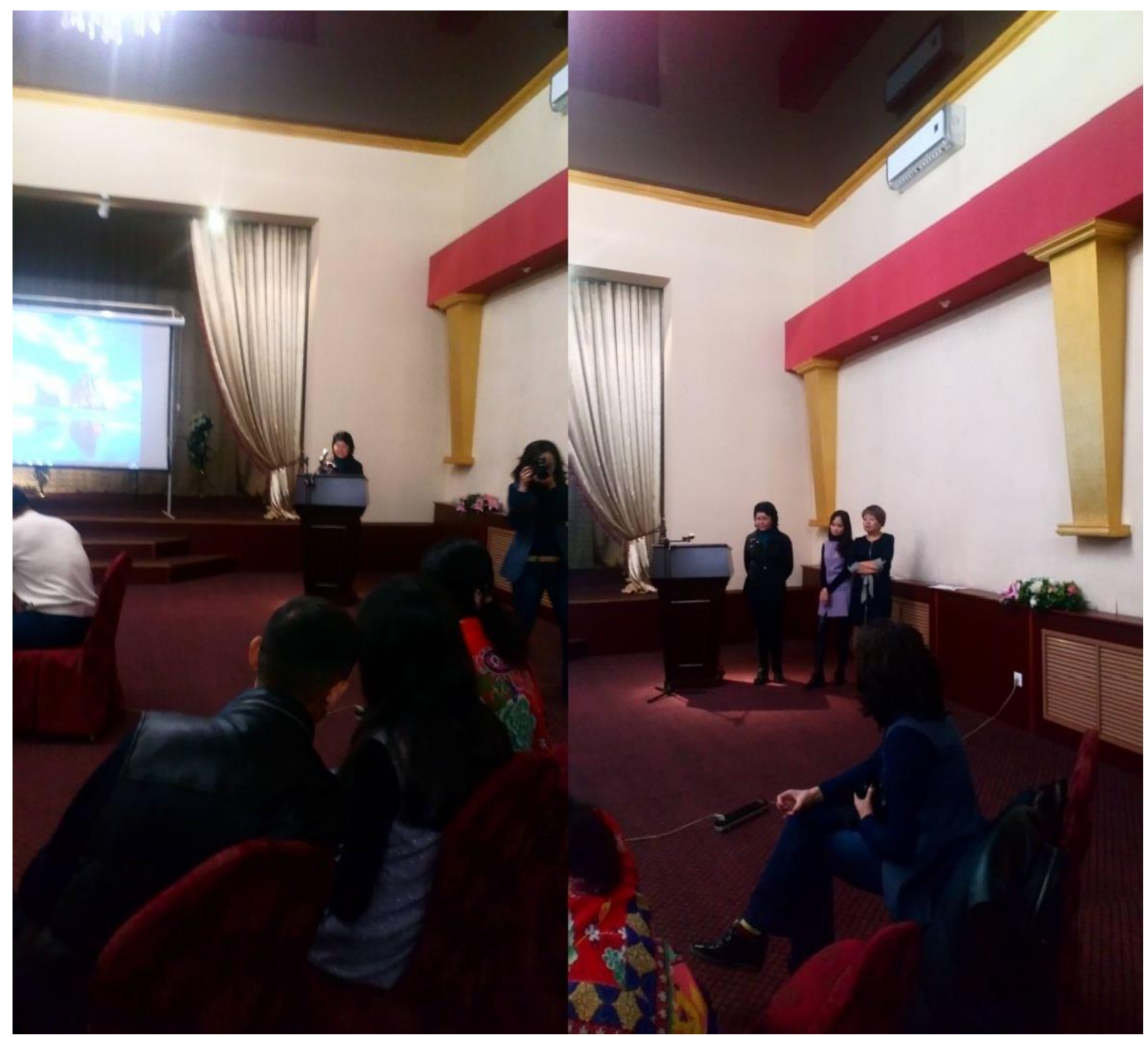

Figure 4. Team The Girls: Roza Taimanova, Erkezhan Kalshabai,Gulnara Nurgalivea: performing - final presentation of project

The social part of the program included a welcome dinner and opening ceremony, but also cultural events - a visit to the Polkovnichy Island, were the monument "Stronger than Death" and "Peace" stella were erected in memory of the victims of the Semipalatinsk Nuclear Test Site. The Memorial Square serves as the venue for an annual anti-nuclear rally with the participation of foreign guests. And a visit to the literary- memorial museum and former residence of F.M. Dostoyevsky, a historic wooden house built in 1838. 

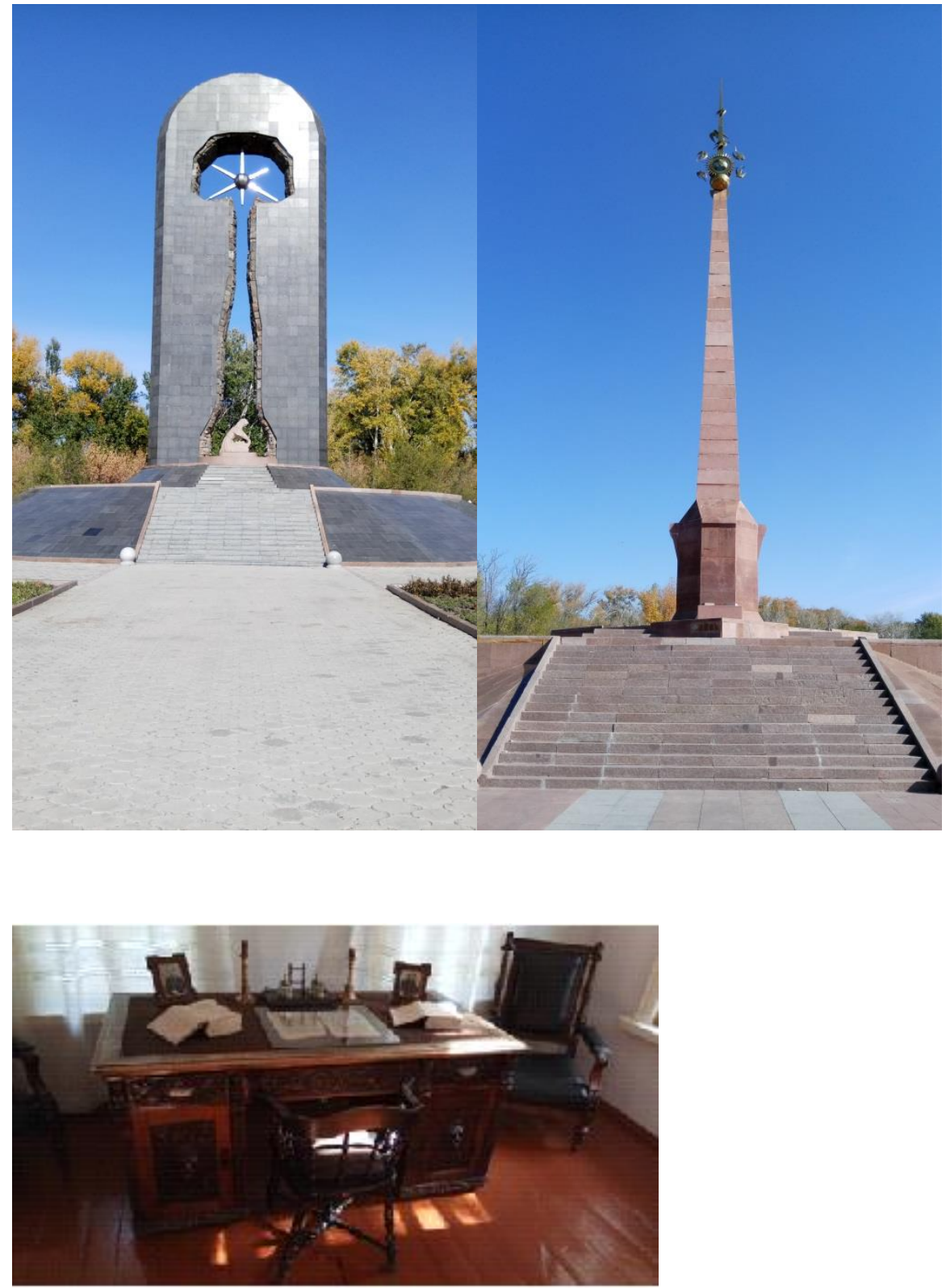

Figure 5. Cultural program: Polkovnichy Island, monument "Stronger than Death" and "Peace" stella in memory of the victims of the Semipalatinsk Nuclear Test Site and Museum of Fedor M. Dostoyevsky

The participants and faculty visited the Semey State Medical University: an educational and clinical center where students are trained using high-tech interactive patient simulation and medical mannequins, virtual reality surgical training simulators, models used in the educational process. The guests were given the opportunity to listen to the heart sounds on the cardio-pulmonary simulator patient training simulator (torso model) with computer support for clinical training in cardiology and pulmonology Harvey. We saw the operation on the virtual simulator LapSim and the virtual simulator arthroscopy ArtroVR. The guests also saw the development of the clinical case "Neonatal Resuscitation" on the interactive dummy of the newborn Hall. 


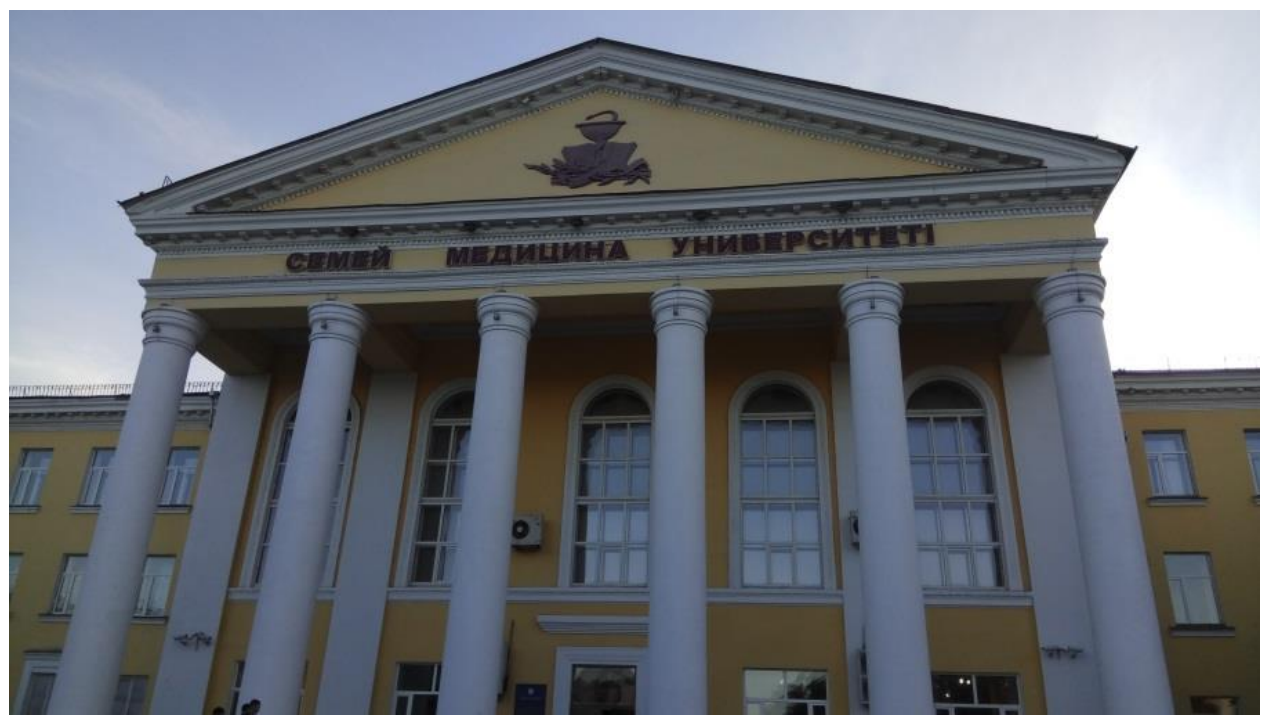

Figure 6. Semei Medical State University(upper picture)

Although the schedule was tense, and the teams worked from early morning until late at night, participants and teachers still had the opportunity during short breaks to enjoy walks in a unique pine forest.
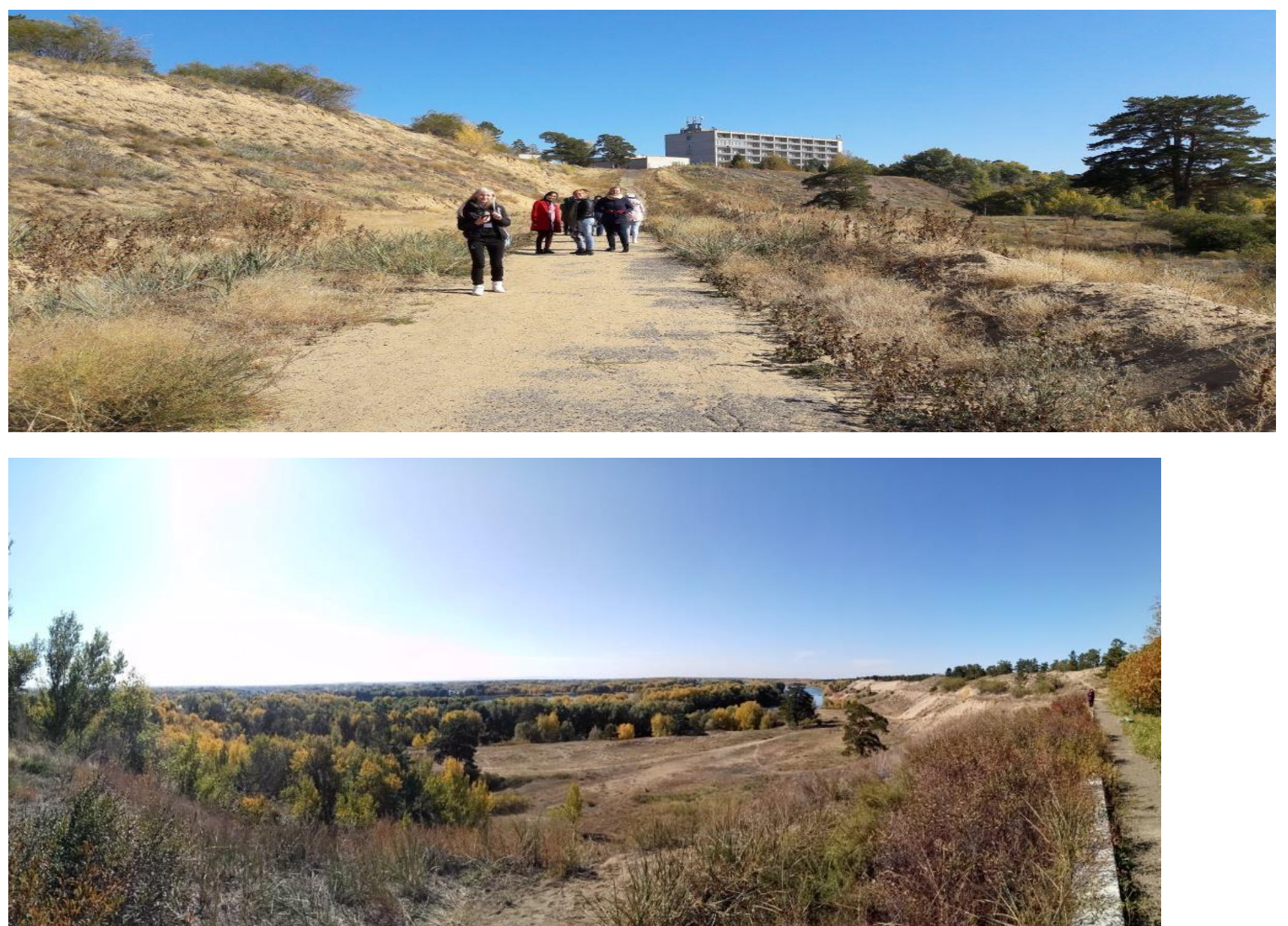

Figure 7. Enjoying nature during brief breaks between workshops 


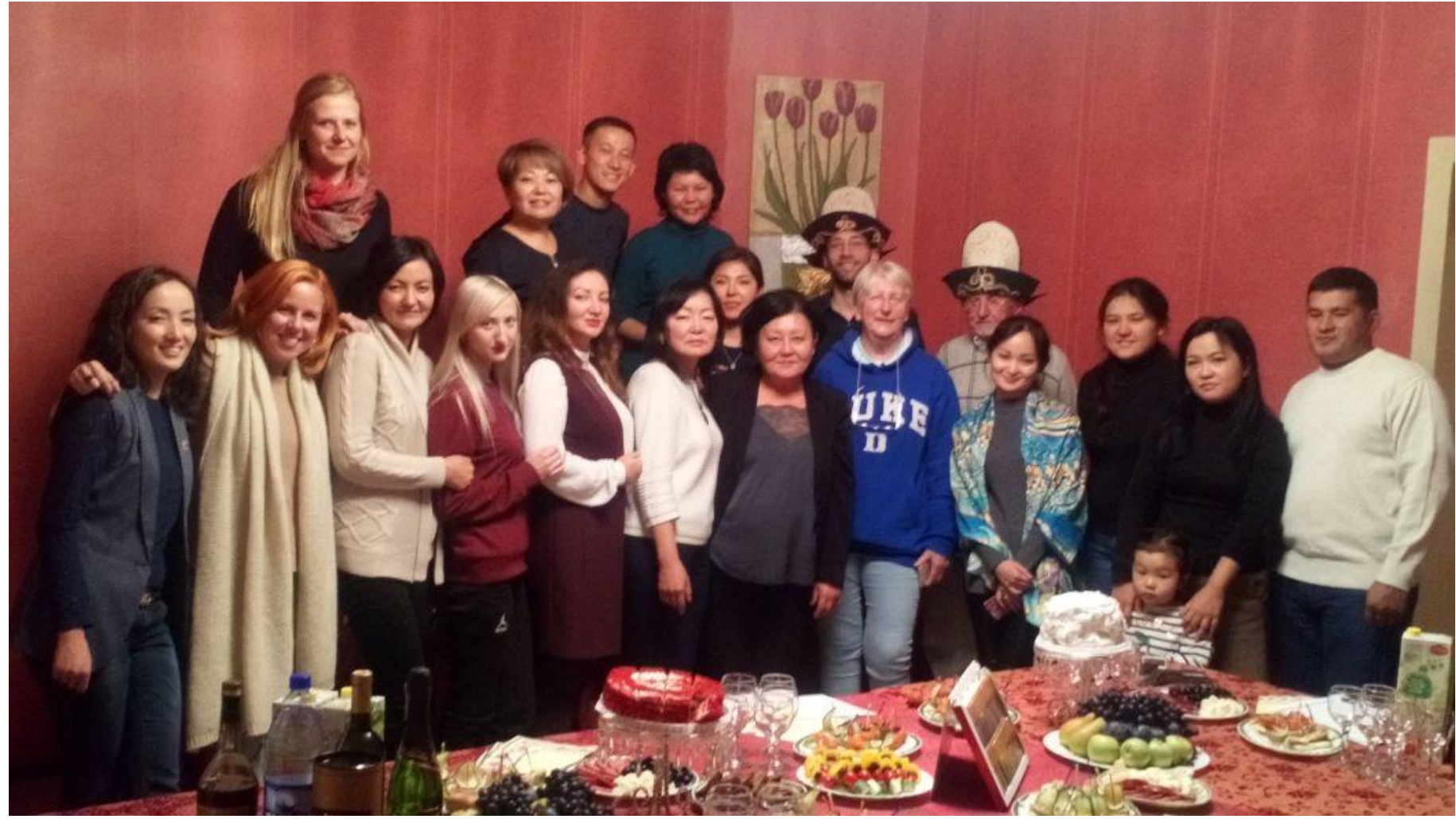

Figure 8. Farewell dinner: $1^{\text {st }}$ raw: Aygerim Musina (Faculty), Michaela Vancova, Assem Makhatova, Alexandra Selivestrova, Zuhra Sultanova (Faculty), Raikhan Tuleyutayeva (Faculty), Gulmira Kudaiberdieva (Faculty), Ljuba Bacharova (Faculty), Erkezhan Kalshabai, Roza Taimanova, Laura Pak (Faculty), Samatbek Abdrahmanov, $2^{\text {nd }}$ raw: Natalia Kopuncova, Gulnara Nurgalieva, Ernar Mamyrov, Dinara Alibekova, Jonathan Lipton (Faculty), Vladislav Bacharov (Observing Faculty)

On the last day the participants held their final presentation of the group projects. This was followed faculty presentations (Jonathan Lipton and Ljuba Bacharova) summarizing the group projects and illustrating the lessons learned during the workshops, both in entertaining and in educational format.

Then followed the ceremony of awarding certificates and a farewell celebration.

Below are the comments received from the participants of the research school. We would like to thank the participants for their tremendous enthusiasm and dedication to acquire and develop skills in research project development, teamwork, interdisciplinary and international collaboration.

Dinara Alibekova - Taraz, Kazakhstan:

I was told about IRIS by my husband, who participated in this school last year in Taraz. He was very impressed and now I understand why, because I have a lot of positive emotions, and gained a lot of information! I received both concrete practical advice that can be applied immediately, and new information that you do not yet know what to do, but you feel its value and usefulness. Upon arrival home, I will definitely review my research protocol to apply the knowledge gained. In general, after the seminar, the horizon of my knowledge has significantly expanded!

Gulnara Nurgalieva -Semey, Kazakhstan:

The school was very interesting and informative, despite the fact that some of the information was already known to me. Many aspects of writing the research protocol gave food for thought and allowed a new look at my research protocol, which I will definitely use in my dissertation. In addition, the school for me personally became an incentive for a new stage in my professional life. The school taught me how to work in a team. Very warm, friendly atmosphere, professionalism of our teachers. One cannot fail to note the "brainstorm" in both intellectual and lexical (using English) activity, which ultimately brought great satisfaction, which undoubtedly was experienced by all participants of the seminar. I would very much like to continue studying at this school on interpreting the results and publishing the manuscript in international peerreviewed journals. Thank you! 
Sasha Selivestrova - Semey, Kazakhstan:

in the beginning I did not understand some of the points and questions, but in the end I was able to understand what was expected. This was useful for me, it will help me to write scientific articles. Erkezhan Kalshabai - Semey, Kazakhstan:

First of all, I wanted to say thank you very much! Being in the internship I am already interested in science and would like to continue in this direction. But I felt a lack of knowledge and had questions about how to properly write scientific articles. Thanks to the school, I found answers to my questions and understood my mistakes. I think schools were a good start to continue research.

Ernar Mamyrov - Semey, Kazakhstan:

The received knowledge should be used as soon as possible, start writing an article for publication in international journals. After we start writing articles, we will face certain difficulties and questions will arise. I believe that it is necessary to repeat the IRIS session - to work on these issues and to disassemble additional topics.

Samatbek Abdrahmanov - Semey, Kazakhstan:

I liked the teaching method based on communication and interactive discussion. Faculty with their leading questions asked us to step by step to reach the truth. I significantly improved my level of English and realized that there is still a lot to learn in the English language, and the need to further. I liked the rapid pace of training, the rapid introduction to the course and the high level of standards.. Especially liked the completion of the school, when we received all the acquired knowledge in the school in the final main goal of "project protection". The school helped me understand the philosophy of conducting scientific research and writing an international publication. I received a lot of useful and interesting information that will help me in the future to carry out my basic scientific work. I can now appreciate the main points in which protocols for scientific research in the postSoviet countries differ in comparison with other countries. And of course it was sad in the end, I did not want to part with other participants, we made friends. Having studied at school with my colleagues from different countries and regions of Kazakhstan, acquired a lot of new friends.

Assem Makhatova - Semey, Kazakhstan:

I'm very glad that I became a participant of your school. The knowledge that we got in this school, they are priceless and I hope they will be useful to me in my research work. Besides, I got a lot of experience in learning English. Thanks to your school, I improved my English. At first it was difficult for me to understand, but in the end I understood every word. I hope that your school will be held in our city annually. I'm grateful to the IRIS course, thank you very much.

Roza Taimanova - Almaty, Kazakhstan:

I am happy to have participated in IRIS. Firstly, I got a lot of new knowledge about the structure of the research work, which will be useful to me. Secondly, I met wonderful people and got a lot of positive and positive emotions from communicating with all the participants. Thirdly, it was my first experience of communication in an English-speaking environment, thanks to which I improved my English.

Michaela Vancova - Trencin, Slovakia:

I heard about the IRIS from Ljuba and when she invited me I said "yes". It was great experience for me! I'm really happy to be here, to meet a lot interesting people. During these days we learned to plan the research protocol ourselves, to think clinically, we learned to work in a team.

Natalia Kopuncova - Trencin, Slovakia:

I'm glad that I became a member of this school. I have learned much useful information. What was new for me I learned how to conduct and plan research from the position of conventional researchers and practical doctors. Whereas my previous experience is to to carry out the clinical studies on the basis of prepared protocols.

Aigerim Makhatova - Semey, Kazakhstan:

I learned about the IRIS school from Aigerim, she invited me. Last year, Aygerim and Zuhra visited this school in Taraz and got excited about the idea of holding a session here in Semey, and giving them IRIS here. I'm very happy that I became a participant. At some moments it was difficult, sometimes the questions of the faculty simply confused us and confounded us, but it was very useful and necessary . We learned how to plan and build all the stages of research correctly, I got a lot of tips about how to write manuscripts and publish them in international journals. Thank you dear Faculty!

Peer-review: Internal

Conflict of interest: None to declare

Authorship: all fulfilled criteria

Acknowledgement and Funding: None to declare 


\section{References}

1. Davis TH, Wagner GS, Gleim G, Andolsek KM, Arheden $\mathrm{H}$, Austin R, et al. Problem-based learning of research skills. J Electrocardiol. 2006;39:120-8.

2. Bacharova L. The Scientific Summer School in Slovakia Liptovsky Jan June 20 - 25, 2006. J Electrocardiol. 2006;39:437-9.

3. Bacharova L. The Scientific Summer School in Turkey 2007 Istanbul - Silivri June 30 - July 5, 2007. Anatol J Cardiol. 2007;7:360-2.

4. Bacharova L, Kirchnerova J. Continuous international network building to promote scientific publication: Scientific Summer School, Pezinok, Slovakia, May 25-30, 2008. Anatol J Cardiol. 2008;8:319-21.

5. Misak A, Bacharova L. The early role of scientific journals in supporting young scientists to become independent researchers; Report on Scientific Summer Schools held in Slovakia and Macedonia in 2008. J Electrocardiol. 2008;41:448-9.

6. Skrak IP, Maricic S. "Train the Trainers"Scientific Summer School June 15-19, 2009 Trilj Croatia. J Electrocardiol. 2009;42:471-2.

7. Hugo V. 2009 Scientific Summer School, Poland. J Electrocardiol. 2009;42:700.

8. Bacharova L, Hakacova N. Building networks for enhancement of scientific/research literacy: The Scientific Summer School 2009 in Szczepanow, Poland. Anatol J Cardiol. 2009;9:433-4.

9. Hakacova N, Baysan O, Bell SJ. Problem-oriented education and cross-cultural collaboration: experiences and comments on the Scientific Summer School in Turkey. Anatol J Cardiol. 2010;10:388-9.

10. Kudaiberdieva G, Wagner G, Bacharova L, Timuralp B, Inan M. Progress of International Scientific Summer School in Turkey from 2007 to 2010: On the eve of the 2014 event. Balkan Med J. 2014;31:1.

11. Bacharova L, Kudaiberdieva G, Wagner GS. International Summer School Initiative: Supporting international networking and collaboration. Bulletin KSMA. 2015;1:167-71.

12. Lipton J, Altymysheva A, Bacharova L, Dzhumagulova A, Koca C, Kudaiberdiev $T$, et al. International Research Interdisciplinary School 8-12 June 2015, Bosteri, Cholpon-Ata, Issyk-Kul, Kyrgyzstan. Anatol J Cardiol 2016; 15: 694-700.

13. Bacharova L, Kudaiberdieva G, Misak A, Hakacova $\mathrm{N}$, Timuralp B, Wagner GS. The effect of International Scientific Summer School research training on scientific productivity of trainees. Int J Cardiol. 2014 Aug 13
13. Wagner G, Bacharova L, Timuralp B, Kudaiberdieva G, Uzun C, Inan M, Misak S, Kristúfek $P$, Bernadic M. Statement from the International Scientific Summer School Collaboration Group. J Electrocardiol. 2014;47:126-7. 